See Article page XXX.

\section{Commentary: Cashing in chips}

\author{
Craig R. Smith, MD
}

Rhee, Park, and Lee ${ }^{1}$ have shown that the AtriClip device (AtriCure Corp) can be used to occlude the left atrial appendage (LAA) through minimally invasive approaches. Ninety-seven percent of their 108 cases were done through a right thoracotomy. The technique they describe for applying the clip from that approach makes me admire their courage and skill. Retracting the aorta and pulmonary artery anteriorly to gain access through the transverse sinus, then manipulating the appendage with traction sutures, sounds like operating at the bottom of a Pringle's can with chopsticks. Approached from the front, the Atriclip earring is mindlessly simple to apply, so mindless that even I use it. It's a piece of jewelry that says "appendage occluded" and makes cardiologists feel so much better, even as they write refills for warfarin.

The authors have described the procedure and their results clearly and without hyperbole. I was surprised that $7.8 \%$ of their patients had incomplete occlusion, but that may be explained by the rigor of their assessment. A series of 108 cases provides reasonable evidence of feasibility but is far too underpowered to support safety claims, particularly for a rare complication like stroke-and they had 2 neurologic events $(1.9 \%)$.

This is nice demonstration of feasibility that's underpowered, and the Commentary I was invited to write didn't seem necessary. I was about to click "decline" when I noticed this comment from the Associate Editor: "The report is valuable and adds to the accumulating evidence that LAA closure at the time of cardiac surgery in patients with atrial fibrillation is beneficial in reducing stroke."

\footnotetext{
From the Department of Surgery, Vagelos College of Physicians \& Surgeons of Columbia University, Columbia University Irving Medical Center of New York Presbyterian Hospital, New York, NY.

Disclosures: The author reported no conflicts of interest.

The Journal policy requires editors and reviewers to disclose conflicts of interest and to decline handling or reviewing manuscripts for which they may have a conflict of interest. The editors and reviewers of this article have no conflicts of interest.

Received for publication Nov 10, 2021; revisions received Nov 10, 2021; accepted for publication Nov 16, 2021.

Address for reprints: Craig R. Smith, MD, Department of Surgery, Vagelos College of Physicians \& Surgeons of Columbia University, Milstein Building 7-435, 177 Fort Washington Ave, New York, NY 10032 (E-mail: crs2@cumc.columbia.edu).

J Thorac Cardiovasc Surg 2021;

$0022-5223 / \$ 36.00$

Copyright (C) 2021 by The American Association for Thoracic Surgery

https://doi.org/10.1016/j.jtcvs.2021.11.036
}

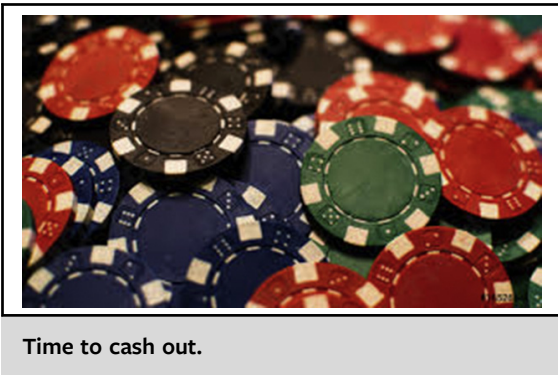

CENTRAL MESSAGE

AtriClip can be applied through a

right thoracotomy.

This earnest little report does nothing of the kind! The authors aren't even presuming to show that LAA closure reduces stroke. This is exactly the problem with this slippery field. Belief drove our Editor to throw this report into the bucket of "accumulating" evidence.

No one wants to hear that from me again. My last outing ${ }^{2}$ provoked my friend Jim Cox, 81st president of the American Association for Thoracic Surgery, to chastise me in a carefully reasoned 3-page Expert Opinion. ${ }^{3}$ He began by saying: "Being a New Yorker, Dr Smith may not be familiar with the old southern adage "never kick a cow chip on a hot day'.... I believe he has kicked a hot chip with his recent Appendacide editorial." I may be a New Yorker now, but I've walked through quite a few pastures in my day. Maybe not as hot as southern pastures, but I've seen how those chips accumulate. When cowed by a pasture full of chips, I doubt I'm sophisticated enough to tell a cow chip from a bull chip. All I've been trying to do is put the chips back in the ungulate.

\section{References}

1. Rhee Y, Park SJ, Lee JW. Epicardial Left atrial appendage clip occlusion in patients with atrial fibrillation during minimally invasive cardiac surgery. J Thorac Cardiovasc Surg. 2022. XX:XX-X.

2. Smith C. Appendacide! Alas, poor auricle.... J Thorac Cardiovasc Surg. 2019 157:1000-3.

3. Cox J. Appendacide? Really? J Thorac Cardiovasc Surg. 2020;159:853-6. 